\title{
XXXI. A portable aëro-mercurial tide-gauge
}

\section{K. Honda}

To cite this article: K. Honda (1905) XXXI. A portable aëro-mercurial tide-gauge, Philosophical Magazine Series 6, 10:56, 253-259, DOI: $\underline{10.1080 / 14786440509463369}$

To link to this article: http://dx.doi.org/10.1080/14786440509463369

册 Published online: 16 Apr 2009.

Submit your article to this journal $2 \pi$

Џ Article views: 2

Q View related articles $₫$ 
The principal results which have been obtained in this paper may be summarized as follows :-

(1) The hypothesis that recombination only takes place after the kinetic energy of the ions has been reduced by collision with neutral molecules, when the ions are very near each other, affords a satisfactory explanation of the variation of the rate of recombination with the gas-pressure.

(2) The results indicate that practically every ion which makes a collision with four molecules becomes fixed; that most of those which make only three, and about one-sixth of those which make only two, collisions, recombine. The terms with fewer collisions become more important at low pressures.

(3) The quantity obtained by dividing the coefficient of recombination by the sum of the velocities of the two kinds of ions, when expressed as a function of the pressure, is found to depend, in the cases of different gases, on a single parameter, which is the mean free path of an ion in the gas in question at some definite pressure.

(4) An ion in carbon-dioxide at high pressures probably contains the same number of gas molecules as an ion in air.

XXXI. A Portable Aëro-mercurial Tide-Gauge. By K. Honda, Rigakuhakushi *. [Plates III. \& IV.]

7 HE novel form of tide-gauge, which is a modification of Richard's hydrometer, or of $W$. Seibt's tide-gauge $\dagger$, consists of a diving jar, a narrow lead (or copper) tubing and a recording apparatus.

Fig. 1 shows the diving jar. vessel made of brass, $12 \mathrm{~cm}$. high and $12 \mathrm{~cm}$. in diameter; it is screwed into a heavy lead disk D. By the tube $a$, water enters the vessel and compresses the enclosed air. The vessel A communicates with the recording apparatus by means of a brass tube $b$ and a long lead tubing $l$ (internal diam. $=3 \mathrm{~mm}$. in $\mathrm{my}$ case); the brass tube is bent in a form as shown in the figure for convenience of transporta$A$ is a closed cylindrical Fig. 1. tion.

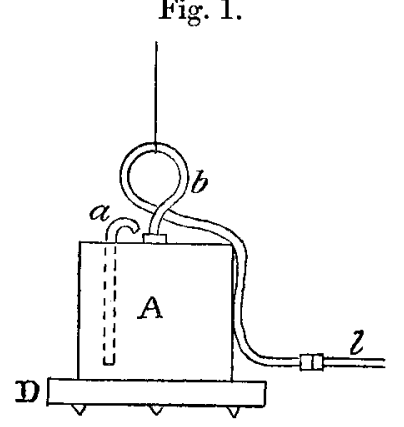

* Communicated by the Author.

+ Seibt, Instrumentenkande, xvii. p. 81, 1897. 
Fig. 2 shows the recording apparatus. The lead tubing $l$ is tightly connected to a glass vessel $B(3.5 \mathrm{~cm}$. in diam.), which is again connected, by means of a thick caoutchouc tube, to a glass tube C $(1 \cdot 8 \mathrm{~cm}$. in diam.). The two arms of the U-shaped system are partially filled with mercury, and the pressure of the enclosed air is balanced by the pressure due to the difference in the heights of the two mercury columns. The change of pressure caused by the change of the waterlevel above the diving jar, appears then as the motion of the mercury column in the tube C.

To record the motion of the meniscus, the following arrangement ${ }^{*}$ is nsed. A float made of a hollow ebonite box fits

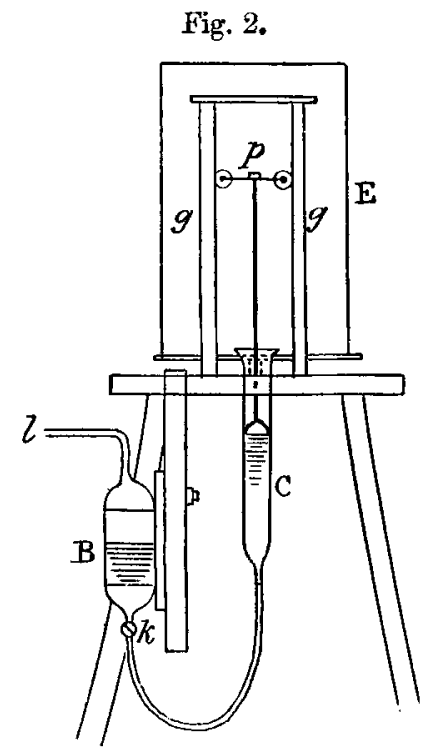
loosely into the open arm of the tube. Upon this, a thin aluminium rod is vertically erected. A pen-holder $p$, which carries two arms perpendicular to the pen, is fixed horizontally on the upper end of the rod. At the end of the arms, friction-wheels are attached which roll in V-shaped grooves of two vertical guides gg. In this way, the pen is constrained to move smoothly in a vertical line. Though the pen is always pressed against the recording cylinder $\mathbf{E}$ by a weak spring, the friction is quite insensible. The recording cylinder $(20 \mathrm{~cm}$. high and $9.4 \mathrm{~cm}$. in diam.), which contains the clock-work inside it, is vertically placed just behind the two vertical guides and revolves once per day about its fixed axis. The zigzags of the curves recorded on the cylinder, which are due to the surface waves of short periods, may conveniently be eliminated to a desired degree by turning the cock $k$ through a suitable angle.

Fig. 3 is the photograph of the apparatus ready for setting ; the reduction is one-sixth of the natural size.

The relation between the change of water-level above the

* K. Honda, Y. Yoshida, and T. Terada, Reports of the Tökyō PhysicoMathematical Society, vol. ii. no. 16, p. 222; Phys. Zeitschrift, no. 4, p. $115,1905$. 
Fig. 3.

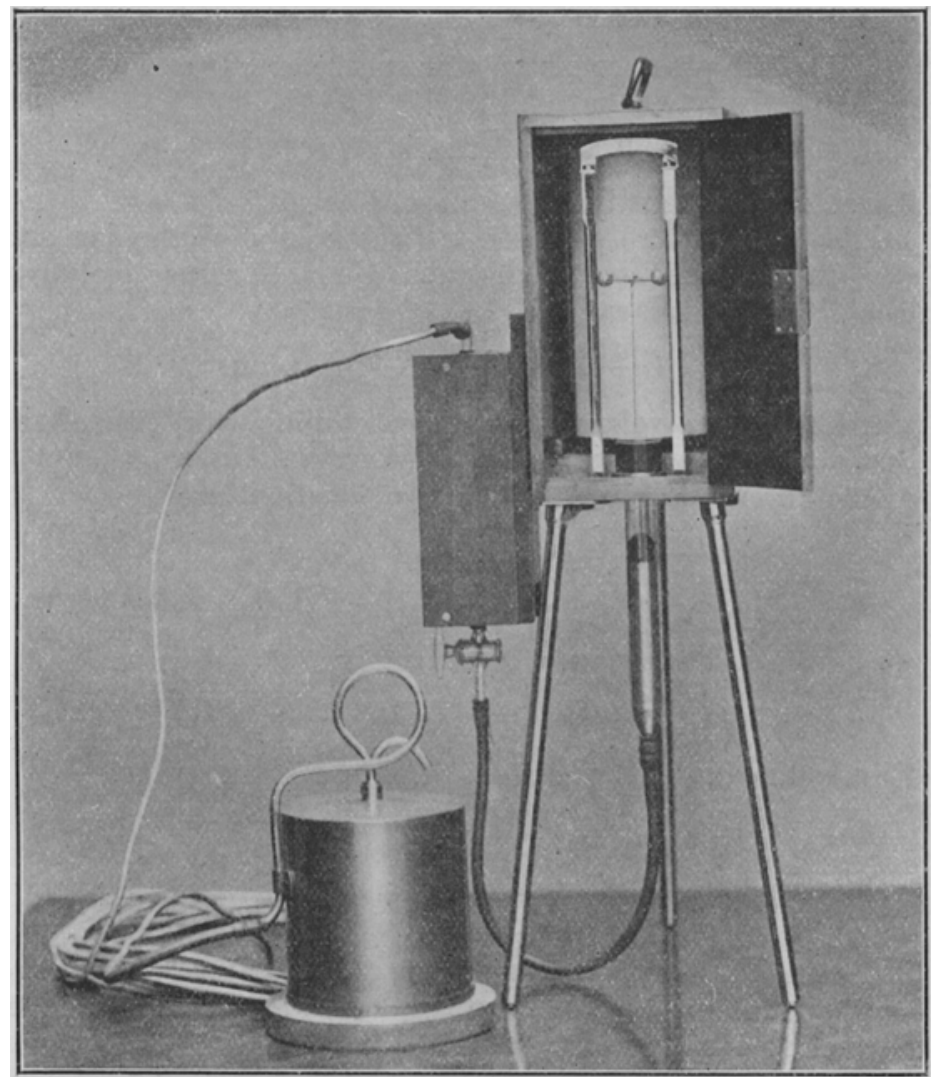

Fig. 4 .

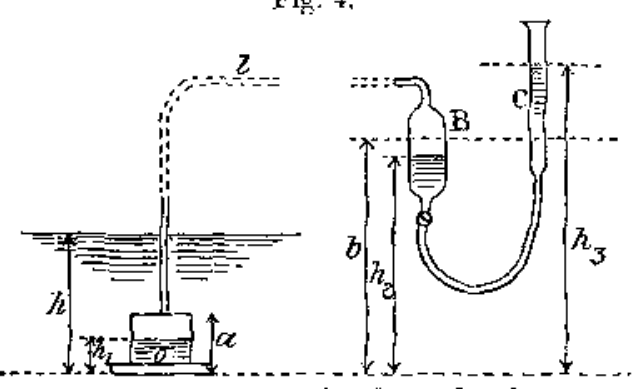

jar and the mereury meniseus in the tube 6 can be found in the following way :-

fot $h, h_{1}$ (fig. 4) be the levela of the water above and inside 
the jar respectively; $h_{2}, h_{3}$ be the levels of mercury in the tubes $\mathrm{B}$ and $\mathrm{C}$. Let $b$ be the common height of the mercury in the tubes, when the jar is not dipped in the water. If II and $\mathrm{P}$ be the pressure of the atmosphere and that within the jar respectively, we have

$$
\mathrm{P}=\Pi+h-h_{1}=\rho\left(h_{3}-h_{2}\right)+\Pi,
$$

where $\rho$ is the density of mercury.

If $s_{1}, a$ be the cross-section and the height of the jar, and $s_{2}, s_{3}$ the cross-sections of the tubes $\mathrm{B}$ and $\mathrm{C}$ respectively, we have, by Boyle's law,

$$
\mathrm{P}\left\{s_{1}\left(a-h_{1}\right)+v+s_{2}\left(h_{-}-h_{2}\right)\right\}=\text { const., }
$$

where $v$ is the volume of the lead tubing, plus that of the part of the tube B lying above the level $b$.

The differentials of the above two equations are

$$
\begin{aligned}
& d \mathrm{P}=d h-d h_{1}=\rho\left(d h_{3}-d h_{2}\right), \\
& \left.d \mathrm{P}\left\{s_{1}\left(a-h_{1}\right)+v+s_{2}\left(b-h_{2}\right)\right\}-\mathrm{P}\left(s_{1} d h_{1}+s_{2} d h_{2}\right)\right)=0 ;
\end{aligned}
$$

we have also the equation of continuity

$$
s_{2} d h_{2}=-s_{3} d h_{3} .
$$

Eliminating $d l_{1}, d h_{3}, d \mathrm{P}$ from these equations, we get

$$
\frac{d h_{3}}{d h}=\frac{s_{1} \mathrm{P}}{\rho\left(1+\frac{s_{3}}{s_{2}}\right)\left\{s_{1}\left(a-h_{1}\right)+v+s_{2}\left(b-h_{2}\right)+s_{1} \mathrm{P}\right\}+\mathrm{P} s_{3}} .
$$

Since the first three terms in the denominator of the above expression are very small compared with the fourth, we have, neglecting these small terms,

$$
\frac{d h_{3}}{d h}=\frac{1}{\rho\left(1+\frac{s_{3}}{s_{2}}\right)+\frac{s_{3}}{s_{1}}} .
$$

Hence the motion of the mercury meniscus in the tube $\mathrm{C}$ is practically proportional to the change of water-level. We may also infer from the exact expression for $d h_{3} / d h$ that the volume of the lead tubing need not be small compared with that of the jar. Even, if the volume of the tubing is equal to that of the jar and the change of the water-level exceeds $10 \mathrm{~m}$., the value of $d h_{3} / d h$ in my apparatus remains constant up to 0.6 per cent., which is sufficient for practical purposes. Hence the recording apparatus can be set up at a considerable distance from the beach. 
It is evident that the reduction-factor $\frac{d h_{3}}{d h}$ of the apparatus may have any value whatever, which is less than $\frac{1}{\rho}$, by suitably choosing the values of $s_{1}, s_{2}, s_{i ;}$, In my case it was 1 16.87 . It is easy to find experimentally the value of the factor, by raising the immersed jar by a known height and comparing this height with the vertical line recorded on the cylinder.

The effect of temperature may be calculated in a similar way. For this purpose, the product of the volume and the pressure in Boyle's law must be put equal to RT, where $T$ is the absolute temperature and $\mathrm{R}$ a constant. Here $h$ is considered to be constant; we have the equations

$$
\begin{aligned}
& d \mathrm{P}=-d h_{1}=\rho d h_{3}\left(1+\frac{s_{3}}{s_{2}}\right), \\
& \rho d h_{3}\left(1+\frac{s_{3}}{s_{2}}\right)\left\{s_{1}\left(a-h_{1}\right)+v+s_{2}\left(b-h_{2}\right)\right\}-\mathrm{P}\left(s_{1} d h_{1}+s_{2} d h_{2}\right)=\mathrm{R} d \mathrm{~T}, \\
& s_{2} d h_{2}=-s_{3} d h_{3} .
\end{aligned}
$$

Eliminating $d h_{1}, d h_{2}, d \mathrm{P}$, we have approximately

$$
d \mathrm{~T}^{i}=\frac{\mathrm{R}}{\mathrm{P}\left\{\rho\left(1+\frac{s_{3}}{s_{2}}\right) s_{1}+s_{3}\right\}} \doteqdot \frac{\mathrm{R}}{{ }_{s_{1} \rho} \mathrm{P}\left(1+\frac{s_{3}}{s_{2}}\right)} .
$$

If we neglect $v$ in comparison with the volume of the jar, $\mathrm{R}$ is equal to $\mathrm{P}_{s_{1}} a / \mathrm{T}$; hence

$$
\frac{d l_{3}}{d \mathrm{I}^{\prime}}=\frac{a}{\rho \mathrm{T}\left(1+\frac{s_{3}}{s_{2}}\right)} .
$$
In my case, $a=12 \mathrm{~cm} ., \rho=13 \cdot 6$, and $1+\frac{s_{3}}{s_{2}}=1 \cdot 26$; hence
at $10^{\circ} \mathrm{C}$.,

$$
\frac{d h_{3}}{d \mathrm{I}}=0.0025 \mathrm{~cm} \text {. }
$$

When the temperature changes, the vapour-tension also changes; but the change of vapour-tension per degree rise of temperature is about $1 / 3$ the change of pressure due to the thermal expansion of air. Hence as the combined effect of these two, we may take

$$
\stackrel{d h_{3}}{d \mathrm{~T}}=0.0033 \mathrm{~cm}
$$

Phil. Mag. S. 6. Vol. 10. No. 56. Aug. 1905. 
I have also experimentally determined this ratio by heating the water in which the jar was immersed, and found $0.004 \mathrm{~cm}$., which agrees fairly well with the above value. The greater part of the enclosed air, which is in the diving jar, is subject to the daily change of temperature by $3^{\circ}$ or $4^{\circ} \mathrm{C}$. of the seabottom. Hence in the degree of accuracy of the present tide-gauge, which records the motion of the mercury meniscus, the correction due to the change of temperature is quite to be neglected.

To estimate the effect of the barometric change, both $h$ and $\mathrm{T}$ are to be considered as constant; we then have

$$
\begin{aligned}
& d \mathrm{P}=d \Pi-d h_{1}=d \Pi+\rho d h_{3}\left(1+\frac{s_{3}}{s_{2}}\right), \\
& d \mathrm{P}\left\{s_{1}\left(a-h_{1}\right)+v+s_{2}\left(b-h_{2}\right)\right\}-\mathrm{P}\left(s_{1} d h_{1}+s_{2} d h_{2}\right)=0 . \\
& s_{2} d l_{2}=-s_{3} d h_{3} .
\end{aligned}
$$

Eliminating $d h_{1}, d h_{2}, d \mathrm{P}$, and neglecting small quantities, we get

$$
\frac{d h_{3}}{d \bar{\Pi}}=-\frac{a-h_{1}}{\operatorname{P\rho }\left(1+\frac{s_{3}}{s_{2}}\right)},
$$

which is, in my case, nearly equal to $-0.04 \mathrm{~mm}$. for the change of barometric pressure by $1 \mathrm{~cm}$. of mercury. Hence the barometric change of $10 \mathrm{~cm}$. in mercury only causes the displacement of the pen not amounting to $1 / 2 \mathrm{~mm}$. Thus in the actual case, the correction due to the barometric change is quite insensible.

In the above calculations, I have neglected $v$ in comparison with the volume of the jar; but in the actual case, the influence of $v$ does not materially affect the above conclusions.

On the coast at high latitude, when the sea often freezes, the present tide-gauge works equally well. The tide-gauge may also be used for recording the tide at sea. For this purpose, it is better to suspend the recording apparatus by a rope, instead of placing it on the deck of a ship. The diving jar is plunged to the sea-bottom ; if the sea be too deep, it is necessary to hang the jar at a suitable depth by means of a buoy fixed by a three-way anchor-rope. To avoid the disturbance of surface waves, it is required to keep the buoy itself at a certain depth in the sea.

In passing, the following remarks may be made about the records obtained by my tide-gauge. Plates III. and IV. are the copy of four of the records obtained in Kiūshu. 
In the bay of Hososhima on the coast of Hiūga, extremely regular undulations appear superposed on the tidal wave; the period varies from $17^{\circ} 7^{\mathrm{m}}$ to $20^{\mathrm{m}}$ according to the tidal phase. The period slightly decreases as the tide passes from the low water to the high. In very calm weather, the amplitude of undulation amounted even to $25 \mathrm{~cm}$. This regular undulation is a stationary oscillation having its node and loop at the mouth and the end of the bay respectively, as actually shown by Y. Yoshida, T. Terada and the author * in several bays on the coast of Sanriku. The period of oscillation is therefore given by the formula

$$
\mathrm{T}=\frac{4 l}{\sqrt{g h}},
$$

where $l$ is the length and $h$ the mean depth of the bay. In the present case, the calculated value is $19^{\mathrm{m}}$, which fairly agrees with the observed one. The change of the period caused by the tidal moiion has also the range which is to be expected from the above formula.

In the bay of Aburatsu in Hiūga, we also observe conspicuous secondary undulations, though they are not regular. 'The period varies from $15^{\mathrm{m}}$ to $22^{\mathrm{m}}$; the amplitude frequently exceeds $13 \mathrm{~cm}$. The calculated period is $17 \mathrm{~m}$, which lies within the range of the observed periods.

'The tidal wave at Kagoshima is generally very smooth ; but frequently distinet secondary undulations of $19^{\mathrm{m}}$ or $24^{\mathrm{m}}$ are observed.

In the bay of Nagasaki, the secondary undulation is so conspicuous that it is usually known as "Abiki." The undulation is not, however, regular; its amplitude often exceeds half a metre. On one occasion, about ten years ago, the amplitude of the abiki amounted even to two metres, and a large number of boats and steamers are said to have been damaged. According to my observations, the period irregularly varies from $25^{\mathrm{m}}$ to $43^{\mathrm{m}}$. Judging from the form of the bay, several nodal lines at the mouth are conceivable; thus the largest and smallest values of the calculated periods are $28^{\mathrm{m}}$ and $41^{\mathrm{m}}$, whose interval fairly coincides with the range of the observed periods.

March 30, 1905.

Tokyo, Japan.

* Honda, Yoshida and Terada, loc. cit. 
Phil. Mag. Ser. 6, Vol. 10, PI. III.

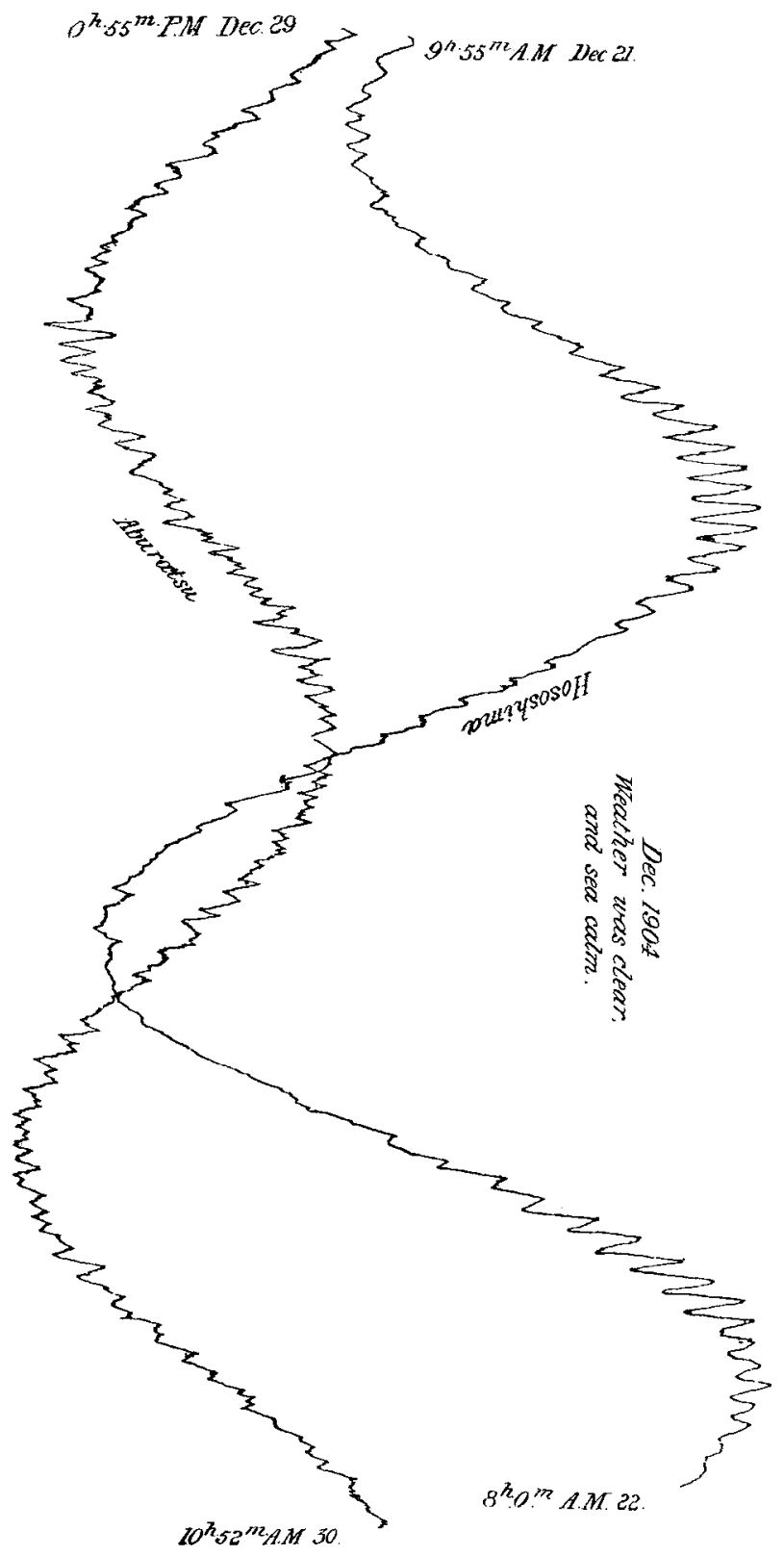


Phil, Mag. Ser. 6, Vol. 10, Pl. IV.

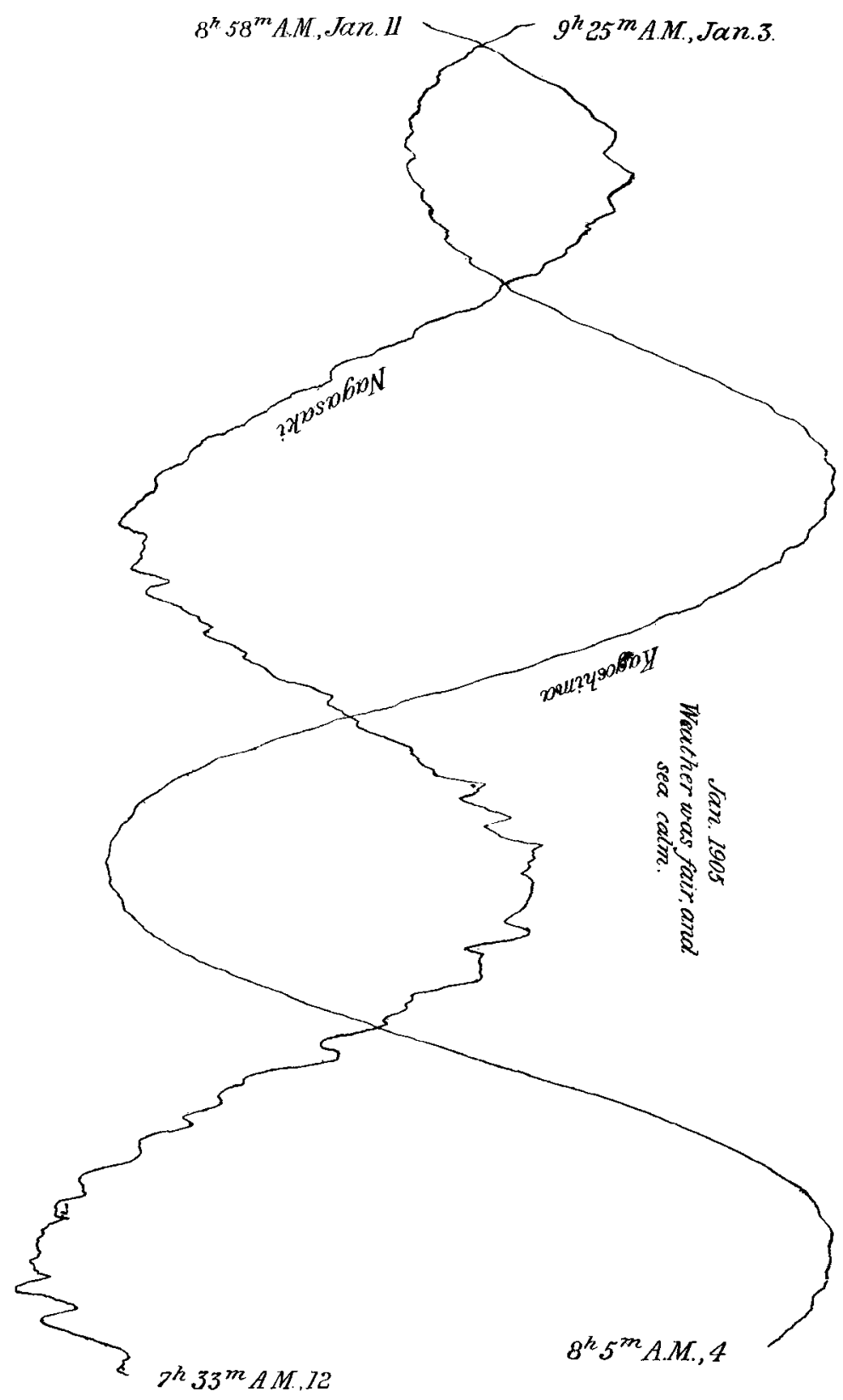

